\title{
The ECGs that will be read around the world-and save lives of sportspeople
}

\author{
Karim M Khan
}

'Having a heart attack? There's an iPhone App for that!' is a true story. We congratulate its inventor Dr David Albert. This issue of BJSM contains advances that are equally exciting and which deserve as much media attention. Sports cardiology is one defining element of the sport and exercise medicine specialty (http://bjsm. bmj.com/content/46/Suppl_1/i2.full). Every one of us has seen an athlete drop dead on film-if not in real life. Whose heart has not stopped on each such occasion? "There but for the grace of God go I" as physician, athlete, or parent. "Houston, we have buy in."

Sports cardiology is a BJSM 'priority topic'. We cover priority topics in each of our three 'pillars'-research, education and implementation. Another way of labelling the 'pillars' is innovation, education and knowledge translation. We use BJSM and partner 'platforms' (eg, see Partnering with BMJ Learning section) to deliver the content. Think of pages such as this one you are reading, the education tab on the BJSM home page with its popular podcasts such as those by Mathew Wilson, Sanjay Sharma, Jonathan Drezner, Jiri Dvorak with Jonathan Tobin, etc. Helping to alert the BJSM community to those riches is our Twitter feed (@BJSM_BMJ) and Facebook page. And our Senior Associate Editor, Evert Verhagen is tasked with developing BJSM's Apps. He will not start with a sports cardiology App but BJSM will land a couple of Apps on this planet before the end of the calendar year.

\section{PARTNERING WITH BMJ LEARNING}

A worldwide team led by Jonathan Drezner (AMSSM) and listed in the 'Seattle Criteria'

Department of Family Practice, The University of British Columbia, Vancouver, British Columbia, Canada

Correspondence to Dr Karim M Khan, Department of Family Practice, The University of British Columbia, Vancouver, BC, Canada V6T 1Z3; karim.khan@ubc.ca paper (bjsports-2012-092067) produced the four key papers in this issue-four papers that examine ECG findings in sports people with more rigour than has previously been managed. The experts assembled in Seattle in 2012, they had the compelling goal of clarifying the complexity of ECG interpretation in athletes among different races to distinguish physiological from pathological findings. The material is very logically dished out in four courses: (1) evidence of electrical disease (bjsports2012-092070), (2) evidence of cardiomyopathy (bjsports-2012-092069), (3) the 'Seattle Criteria' and (4) the old chestnut now with new clarity-the ECG changes that are physiological in athletes (bjsports2012-092068). A great innovation of this team was to embed 'implementation' into the plan from baseline. Thus, each of the papers provides the foundation for online education which will be available (in English initially) for the entire world to view. Because of the generosity of sponsors-such as AMSSM, and FIFA, this material will be free worldwide. The sports cardiology team is partnering with BMJ Learning - a branch of the BMJ Group dedicated to $\mathrm{CME}$ in the imaginative, broad sense of that term. Follow your favourite mobile sites such as AMSSM, FIFA or BJSM among others-to be apprised of this free content as soon as it is available.

\section{PARTNERING WITH THE BMJ}

The BMJ is deservedly an iconic brand and BJSM is delighted to reprint key sport and exercise medicine papers from recent BMJ issues. We launched this in 2008 but had to take a break to clear some backlog. Now with 18 BJSM issues a year, the best of BMJ is back for good! (bjsports-2012-e2672rep). And remember BMJ's active bloggersamong them the evocative and provocative Domhnall MacAuley (@DMacA).
WHAT'S IN A NAME 50 YEARS LATER? A year from now, 2014, would have marked the 50th anniversary of the 'Bulletin of the British Association of Sport and Medicine' had not some iconoclasts decided that a Journal was better than a Bulletin. The 1964 'Bulletin of the British Association of Sport and Medicine' (http:// bjsm.bmj.com/content/1/1/1.full.pdf

+ html) has had various iterations to reach its present title of BJSM. In today's sport and exercise medicine setting, BJSM's lack of ' $E$ ' seems anachronistic. Britain's BASM readily become BASEM, Canada's CASM equally CASEM. The title of BJSM mirrors neither the co-owner society name (BASEM) nor does it reflect the paradigm shift that has justified sport and exercise medicine specialty status in many countries. In 2013, Exercise is Medicine.

Would 'BJSEM' make more sense and more accurately signal to patients, policymakers and professional colleagues that our field of medicine embraces exercise (and physical activity)? Is it time to advance, walk on the spot, or really embrace our past and revert to a mighty 'Bulletin' again? If it's time to advance, then innovators would 'open the diamond' and think bravely-consider options that would add member society value (ie, greater reach and brand value), before refining and making a new choice. The 2013 BJSM Management Meeting heard that BASEM considers BJSM's ratio of 'sports medicine' content to 'exercise medicine' about right. The editors have heard that and are listening. But as for a journal title, the BASEM executive welcomes members' comments on how our sport and exercise medicine community thinks we should ring in our 50th year, so let us know. You can Tweet (@BJSM_BMJ), post a message on Facebook, email, dial, or use Royal Mail.

Competing interests None.

Provenance and peer review Commissioned; internally peer reviewed.

To cite Khan KM. Br J Sports Med 2013;47:121.

Received 19 December 2012

Revised 19 December 2012

Accepted 19 December 2012

Br J Sports Med 2013;47:121.

doi:10.1136/bjsports-2012-092108 